This item was submitted to Loughborough's Research Repository by the author.

Items in Figshare are protected by copyright, with all rights reserved, unless otherwise indicated.

\title{
The politics of aspiration: neo-liberal education policy, 'low' parental aspirations, and primary school Extended Services in disadvantaged communities
}

\section{PLEASE CITE THE PUBLISHED VERSION}

http://dx.doi.org/10.1080/14733285.2011.540441

\section{PUBLISHER}

(c) Routledge (Taylor \& Francis)

\section{VERSION}

AM (Accepted Manuscript)

\section{LICENCE}

CC BY-NC-ND 4.0

\section{REPOSITORY RECORD}

Holloway, Sarah L., and Helena Pimlott-Wilson. 2019. "The Politics of Aspiration: Neo-liberal Education Policy, 'low' Parental Aspirations, and Primary School Extended Services in Disadvantaged Communities". figshare. https://hdl.handle.net/2134/13803. 
This item was submitted to Loughborough's Institutional Repository (https://dspace.lboro.ac.uk/) by the author and is made available under the following Creative Commons Licence conditions.

\section{creative
commons}

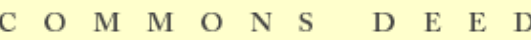

Attribution-NonCommercial-NoDerivs 2.5

You are free:

- to copy, distribute, display, and perform the work

Under the following conditions:

Attribution. You must attribute the work in the manner specified b the author or licensor.

Noncommercial. You may not use this work for commercial purposes.

No Derivative Works. You may not alter, transform, or build upon this work.

- For any reuse or distribution, you must make clear to others the license terms of this work.

- Any of these conditions can be waived if you get permission from the copyright holder.

Your fair use and other rights are in no way affected by the above.

This is a human-readable summary of the Leqal Code (the full license).

\section{Disclaimer 만}

For the full text of this licence, please go to: http://creativecommons.org/licenses/by-nc-nd/2.5/ 


\title{
The politics of aspiration: neo-liberal education policy, 'low' parental aspirations, and primary school Extended Services in disadvantaged communities
}

To cite: Holloway, S.L. and Pimlott-Wilson, H. (2011) The politics of aspiration: neo-liberal education policy, 'low’ parental aspirations, and primary school Extended Services in disadvantaged communities Children's Geographies 9.1: 79-94

\begin{abstract}
Geographical research on education has grown rapidly in both volume and scope during the first decade of the twenty-first century, and one relatively new theme to emerge from this growing literature is that of education and aspiration. Much of the nascent interest in aspiration concerns access to quality schooling and University education. In this paper by contrast we highlight the importance of studying the ways aspirations are (re)produced within the school community. Our empirical focus is on low-income England under New Labour. Here we pursue a two-fold approach: firstly examining how education professionals define parental aspirations for primary-aged children as low; before secondly considering their alternative understandings of appropriate aspirations and the practices through which they seek to promote these, both in school and through the use of Extended Services for parents and children. In conclusion we highlight the importance of inward and outward geographies of education which 'recouple' schools with their social context, and discuss the moral and political ambiguities involved in practices designed to raise aspirations.
\end{abstract}

Key words: Geography; Education; Aspiration; Parenting; Class; Welfare Reform

\section{Introduction}

Geographical research on education has grown rapidly in both volume and scope during the first decade of the twenty-first century (Butler \& Hamnett, 2007; Collins \& Coleman, 2008). This wide-ranging body of literature does not have clearly defined boundaries, and the subdisciplinary structures which help promote other fields of research are largely absent (Hanson Thiem, 2009; Holloway et al., 2010). Nonetheless, the appearance of specialised sessions at the annual conferences of the Association of American Geographers, the Royal Geographical 
Society/Institute of British Geographers, as well as seminar series and independent international conferences such as the one held at Loughborough University in 2009 from which this special issue emerges, are a testament to the active and vigorous interest in this area of research.

One relatively new theme to emerge from this growing literature is that of education and aspiration. We begin in the next section by setting this developing interest in aspiration in the context of existing research on geographies of education. In so doing, we highlight the emergence of interest in aspiration in terms of access to school and higher education, but note the relative paucity of research about the ways aspirations are reproduced through the formal and informal curriculum within schools. Our own study seeks to address this lacuna through a focus on the reproduction of aspirations within primary schools serving low-income areas of England. It takes a two-fold approach, exploring firstly how education professionals define parental aspirations for primary-aged children in these areas as low ${ }^{\mathrm{i}}$, before secondly considering how this group of professionals envisage appropriate aspirations and examining the practices through which they seek to promote these in school. In conclusion we highlight the specific importance of studying aspiration within the school context, as well as the need to undertake research in a manner which links these schools to their global, national and local contexts. Moreover, the moral and political ambiguities of interventions designed to raise aspirations are also discussed.

\section{Geographies of education and aspiration}

A range of research strands are evident in the current literature on geographies of education, lines of enquiry that build upon and extend a relatively long history of research in this area (Hanson Thiem, 2009; Holloway et al., 2010). One key concern for geographers has been the social geographies of educational provision and consumption, with an interest in social justice informing studies of differential access to education, and geographical variations in educational attainment. Initially, most interest was focused on schooling, exposing the poor deal many students from low-income families and minority ethnicities get from state education in advanced capitalist political economies (Freytag, 2003; Johnston et al., 2007; Warrington, 2005), and analysing access to, and the implications of, education for genderand ethnically-diverse young people in the global South (Cao, 2008; Jones \& Chant, 2009; Punch, 2004). More recently growing attention has been paid to higher education. Political interest in widening participation in higher education in the Global North has prompted a 
growing number of geographical studies exploring the processes which facilitate/inhibit different social groups’ entry into higher education and their experiences within it (Holdsworth, 2006; Hopkins, 2006). These can be set against a background, in the UK at least, of broader social science critiques of the tension between the neoliberal and equality agenda in New Labour policy and the need to theorise educational aspirations in social context (Archer, 2007; Burke, 2006). This attention to the experiences of different social groups is also seen in the Global South, where for example Jeffrey et al. (2004) explore the questionable impacts of higher education on future life chances, and in 'global' studies which have traced the ways in which the search for educational advantage fuels transnational migration by higher education students (Waters, 2009). These developments in geographical interest - in the inequalities of school provision and 'parental choice', in political discourses about raising potential higher education students' aspirations, and in the varied consequences of education for different social groups across the globe - are the key routes through which debates about aspirations have begun to emerge in the agenda of geographers (Butler \& Hamnett, this issue; Brown, this issue; Hinton, this issue; but see also McDowell, 2002).

A second strand of research on geographies of education has explored the importance of the formal and informal curriculum in shaping young people as future citizen-workers as well as the (re)production of social difference within schools (see Holloway et al., 2010 for a review). It is noteworthy that the strength of this research thread, with its emphasis on pupils' current experiences as well as future life-worlds, has lead very few geographers to engage in studies of young people's aspirations in the manner that researchers in education studies have done (Cooper, 2009; Strand \& Winston, 2008), teasing out the importance of schooling, parental influence and neighbourhood effects on pupils' educational and employment ambitions (Crozier, 2009; Stewart et al., 2007). Bauder’s (2001: 605) research on the education and career advice given by community-based organisations in an urban US context is perhaps an exception to this trend. Although he does not engage directly with schools, his research does illustrate how cultural interpretations of the neighbourhood context, including the labelling of some youth as 'dysfunctional', shape the formal and informal mechanisms through which these locally-embedded organisations seek to shape young people's future aspirations. This paucity of geographical research about the shaping of aspirations within schools, alongside wider social science calls for a 're-coupling of educational research with context' (Raffo \& Dyson, 2007: 266) in a manner that is demonstrated in Bauder's study, provide the stimulus for the research in this paper. 
Our purpose here then is to contribute to geographical research about the ways aspirations for/of young people are viewed and shaped by education professionals in the school setting. Before we can begin to explore attitudes and practices within schools, however, we first need to understand their position within the wider society. Our research is based in England which is a particularly apposite case study because here the political discourses about aspiration and widening University participation discussed above have, like much wider educational policy (Brehony, 2005), trickled back down the age range into the compulsory stages of the education system, a fact not surprising given the importance of education and aspiration in New Labour political discourse (Raco, 2009).

New Labour prioritised 'education, education, education' in their electoral platform in 1997, and it remained central to their economic and social policy whilst in government until May 2010 (Whitty, 2009). Their emphasis on education needs to be understood in the context of a 'third way' approach to politics, most often framed in terms of 'rights and responsibilities', which has seen the combination of workfare-oriented economic policies and a social agenda focused on inclusion and a desire to reduce specific social inequalities (see Paterson, 2003 for a detailed critique on New Labour educational ideology). As Prime Minister, Tony Blair tied social and economic objectives together in education policy:

The old dispute between those who favour growth and personal prosperity, and those who favour social justice and compassion, is over. The liberation of human potential for all the people, not just a privileged few - is in today's world the key to both economic and social progress (Blair, 1999, cited in Taylor, 2005: 102).

In economic terms, he regarded education as 'our best economic policy’ (Blair, cited in Reay 2008: 644) because ‘human capital is a nation’s biggest resource’ (Blair, 1999, cited in Taylor, 2005: 102) and in the words of the then Secretary of State for Education:

'Learning is the key to prosperity....Investment in human capital will be the foundation of success in the knowledge-based economy...To achieve stable and sustainable growth, we will need a well-educated, well-equipped and adaptable labour force...We need the creativity, enterprise and scholarship of all our people"' (Blunkett, 1998, cited in Taylor, 2005: 102).

Social objectives clearly run side-by-side with these economic aims, as Blair argued that education had the power to 'correct the inequalities of class or background' (Blair, cited in Reay, 2008, 644). Investment in early childhood and school-aged education was designed to provide opportunities for all children to achieve, thereby encouraging social inclusion and social stability into the future. Children for their part were expected to be aspirational. As Tony Blair’s successor New Labour Prime Minister Gordon Brown emphasised: 
“The greater failure is not the child who doesn't reach the stars, but the child who has no stars that they feel they are reaching for" (Gordon Brown, 2007, cited in Gutman \& Akerman, 2008: i).

Raco’s (2009) recent writing on the existential politics of neo-liberal-state agenda sets such political discourses about education and aspiration in context. Raco argues that during the 2000s citizen-state relations have undergone change in England as New Labour sought to shift the nation from a model of expectational citizenship, where the welfare-state is seen as a provider, to aspirational citizenship, where the state is instead seen as an enabler or facilitator. In these aspirational politics, the policy focus is no longer society, rather the aim is to change individual actors so that they might better perform their responsibilities as future citizen-workers. The ideal citizen-subject in this model is based around middle-class norms, with this group’s apparently independent citizenship being used as a yardstick against which to judge other more obviously dependent citizenship practices. As Raco (2009: 443) argues, 'one consequence of the shift to aspirational politics has been the normalisation and mainstreaming of practices and ways of thinking that, in fact, reflect a narrow form of [middle]class-infused consciousness' (Raco, 2009: 443). This is certainly the case in education, where Reay (2008: 643) argues New Labour policies have depended on a notion of an ideal parent who encapsulated 'middle-class resources, dispositions and values'.

This political insistence on the importance of education, both as an economic policy which can produce flexible workers for a dynamic economy, and as a social policy which can challenge entrenched social division by offering opportunities to aspirational children, has an interesting resonance with our recent experiences of fieldwork within primary schools. The research in question was concerned with the implementation of Extended Services (Cummings et al., 2007; DfES, 2005; Wilkin et al., 2003) in primary schools in a provincial English Local Authority (LA), comprising services such as wrap-around childcare from 8am$6 \mathrm{pm}$, enrichment activities for children, and parenting support. As part of this process headteachers were asked through a questionnaire survey about the main challenges facing their school, and low parental aspirations were identified as a persistent problem in those schools serving what we might refer to as low-income, or economically-deprived, areas. This coming together of political discourse which seeks to produce aspirational subjects (Raco, 2009) with empirical experiences of an education system in which professionals are quick to express concerns about low aspirations in economically-marginalised areas is of intellectual interest to us. 
Our aim in this paper therefore is to build upon geographers' nascent interest in aspiration, as well as our own experiences in the field, and explore education professionals' constructions of, and responses to, what they regard as low parental aspiration in low-income areas. In intellectual terms, we want to complement geographical interest in questions about aspirations and access to education which emerged from the first strand of research on educational provision and consumption identified above, with a second strand of interest on the ways aspirations are shaped and understood within school communities, questions which our review of the second strand of research on the curriculum showed have been little studied by geographers. In pursuing this agenda, we are keen to ensure that this form of educational research within schools remains coupled with its context (Raffo \& Dyson, 2007), both in terms of the way schools shape, and are shaped by, the national political context, and as they relate to the local low-income communities they serve. In practical terms the two aims of our paper are therefore: (1) to examine the ways in which education professionals define parental aspirations for children as low in low-income areas, and (2) to explore how they define appropriate aspirations, and the manner in which they seek to achieve these within their schools. Before we turn to our empirical data, however, the next section provides a little more detail about our case study area and the research methods we employed.

\section{Methodology}

The data on which this paper is based were collected as part of a larger study exploring the challenges facing schools serving different socio-economic communities and their implementation of Extended Services. The schools were all located in one provincial Local Authority which we refer to by the pseudonym Hortonshire in order to maintain the anonymity of the Local Authority and those with whom we worked ${ }^{\mathrm{ii}}$. The geography of Hortonshire means that it contains schools serving children from different class backgrounds, whilst overall the Authority roughly conforms to national average with approximately $13 \%$ of children receiving free school meals (DCSF, 2009). Children are living in a mixture of large urban, smaller urban and rural communities, and the provincial nature of the Local Authority is evident in the ethnic make up of its pupils, more of whom are white ( $>95 \%)$ than national averages (87\%) would suggest (ONS, 2005).

The research undertaken here included a questionnaire survey and semi-structured interviews. The questionnaire survey, which asked both about the challenges facing these school communities and their Extended Service provision, was sent to all primary school 
headteachers in Hortonshire. The response rate (following postal delivery and email follow up) was 67\%. We then undertook 34 interviews with headteachers, Extended Services coordinators and Local Authority employees in higher, middle and low-income areas, but in this paper we draw on a sub-sample of 13 of these - 8 headteachers (HT), 3 Extended Services staff (ESS) and 2 Local Authority employees (LAE) - who reflected on the experiences in schools serving low-income communities. The research was subject to full approval by Loughborough University ethics committee, and to ensure anonymity, interviewees were allocated numerical identifiers for use in the storage, analysis and publication of transcript data.

The definition of low-income, like class itself, is clearly contested. In this paper we proceed on the understanding that class encapsulates both a position that might be measured by occupation or earnings, and a subjectivity shaped by (and shaping) social and cultural practices (Gillies, 2006; Stenning, 2008; Vincent et al., 2008). To select case-study schools, however, we needed a proxy for social class on which secondary data was available. We chose Free School Meal (FSM) eligibility, a commonly used measure in the English school context, with the Government making an explicit link between this, poverty and educational attainment (DCSF, 2008). The Office for National Statistics defines a school as 'deprived' if over 30\% of children are eligible for FSM (ONS, 2004) and as such, schools with FSM eligibility over $30 \%$ were classed as low-income ${ }^{\mathrm{iii}}$ in this study. We use the nomenclature low-income rather than working class for the most part in the paper, because we think the label working class obscures great diversity amongst economically less-advantaged groups in the England. So while the areas in which the research was undertaken might well be referred to as working class, we have chosen the label low-income here to emphasise that these are particularly economically disadvantaged, with for example around a quarter of the population of working age being on state benefits, and the areas being characterised as having struggling families in the ACORN ${ }^{\text {iv }}$ classification (CACI, 2010; ONS, 2007). On occasions we compare these families with their middle-class counterparts. In doing so, we are cognisant that the category middle-class is itself heterogeneous, but contend that the distinction between (attitudes to) these low-income families and 'the' middle-class remains insightful in a context where class-specific norms inform the politics of aspiration (Raco, 2009).

The following section of the paper now considers the research findings. It begins by exploring how education professionals interpret parental aspirations for the children as low, 
before going on to explore what they regard as appropriate aspirations and the best way to achieve these through the school setting.

\section{Education and aspiration in schools serving low-income catchments}

\section{Problematising parental aspirations}

Our questionnaire results show that low parental and child aspirations are identified as a challenge by over $90 \%$ of headteachers in schools serving these largely white, low-income areas. These responses were made in the context of an open ended question about the challenges facing children, and it is notable, that low aspirations were often linked bluntly with social and economic deprivation:

Social and economic deprivations. Low parental aspirations

Economic disadvantage, low aspirations.

Area of deprivation / low aspirations

Social deprivation, low aspirations, poor communications.

Lack of aspiration, lack of emphasis on the importance of education, lack of money.

Here headteachers assessments are in line with threads in wider educational research which shows that socio-economic status is a 'key differentiator' (Gilby et al., 2008: 4), with socially and economically disadvantaged and white parents having lower aspirations for themselves and their children (Gutman \& Akerman, 2008); these lower aspirations being shared by children themselves as they grow up (Gilby et al., 2008). By connecting a "lack of aspiration, lack of emphasis on the importance of education, lack of money” together, headteachers represent the largely white, low-income parents as the opposite of idealised middle class parents who are constructed in wider political and policy discourse as having the appropriate aspirations, values and financial resources to support their children (Gillies, 2006; Haylett, 2001).

This somewhat neat convergence of headteachers' views with the results of previous research does not signal an abrupt end to our analysis; rather - in a discipline where there is growing interest in 'working class geographies' (Stenning, 2008: 11) and academic interest in the ways class-specific norms shape policy (Haylett, 2001; Raco, 2009) - it begs more questions than it answers. Specifically, it causes us to ask what exactly are the aspirations of these low-income parents for their children; how/why do education professionals deem these aspirations as low; and what, by contrast, do they envisage as raised or high aspirations. 
Headteachers identify the core elements of parental aspirations for children in lowincome schools as being centred on children's happiness and emotional security, as well as good behaviour:

....most of them really are only wanting them to come and be happy. They are interested in what they're learning and how well they're doing but the most important thing for them is that they're happy and secure. (HT8, emphasis added)

I'd like to say they want it to be better than they had, but not all of them have that aspiration at all. Mainly they want their children to be happy! If their children are happy and they don't give them any grief about anything that's happening at school when they go home, then as far as their parents are concerned it's job done. (HT1, emphasis added)

..they want their children to be able to read when they leave and essential things like that. And they want their children to behave you know, they think that that's a key role for school (HT7)

The labelling of aspirations focused on a child's happiness and good behaviour as low seems somewhat perverse. Aspirations for a child's future happiness are widely shared across all social classes in Britain (Cabinet Office Social Exclusion Taskforce, 2008), suggesting a significant degree of societal agreement on the importance of this. Moreover, this requires considerable emotional investment by working-class mothers, making sure children are safe and maintain a positive sense of self-worth at school, thereby giving children the emotional capital to survive school (Gillies, 2006; Reay, 1998). Gillies (2006) argued that this emotional investment is widely undervalued by educationalists. In this case headteachers do, to a degree, recognise the emotional care low-income parents have in respect to their children's schooling and their desire for children to behave well, but this alone is not regarded as sufficient and in 'mainly' or 'only' wanting this, their aspirations are judged by education professionals to be low.

The reason these otherwise ostensibly virtuous aspirations are negatively judged by headteachers is because this interest in child happiness and behaviour is not often combined by parents with an expectation that their children will do well academically and achieve consequent success in the labour market:

There are very low aspirations parents have for their children here. And for a, it's not for all of them because you know obviously there are some of them who ... want their children [to] do well, they do want their children to go to university, I've got one in year 5 who you know is really keen that he doesn't do what she did, which is great. But generally the parents don't see the worth of anything other than leaving school as soon as possible and earning money... earning money, getting their money however they get it, you know social [state benefits] or whatever (HT5) 
High expectations are being defined by headteachers as learning more than basic literacy skills, progressing into higher education, and following a path through life that is different to their own parents. In other words, parents' aspirations are seen to be low because they do not valorise behaviour and ambitions which underpin middle-class lifestyles (Gilby et al., 2008).

The disjuncture between parents’ own experiences and normative understandings of high aspirations for children is not lost on these education professionals. Class structurationist studies of parental and child aspirations have argued that low aspirations can be an economically rational response to the potential costs and benefits of educational performance (Gutman and Akerman, 2008), while Bourdieu argues explicitly that a person's aspirations are shaped by the likelihood of achieving them (Bourdieu, 1973). Thus whilst it is theoretically possible to distinguish between aspirations (what people hope to achieve) and expectations (what people believe they will achieve), the two often become blurred in academic discussion and daily practice as life experience influences both people's hopes and their likelihood of achieving them (Cabinet Office Taskforce on Social Exclusion, 2008). Some education professionals in this study did show an appreciation for the ways aspirations are shaped through processes of class stratification. This includes, for example, an understanding that parents' relatively poor position in the labour market, and their own poor experiences of schooling, will limit their aspirations for their children:

[The jobs parents do are] mainly low skilled sort of Tesco's and characterised by low pay and the community as well seems to be characterised by quite low aspirations as well. There's not generally as much of an expectation from parents that their children are going to succeed academically. (HT7)

[In this area there are] lots of issues of drug use within families, domestic violence within families, anti-social behaviour of sort of teenage youth culture.... So that kind of gives you a bit of an idea of where we're coming from. Very, very low aspirations of what the children can achieve. Lots of parents who find school quite daunting because they had bad experiences themselves...they really have very low self esteem about what they're capable of and then that reflects on the children you see, they then have low self esteem. (HT2)

the parents haven't high expectations [for the children] because I don't think they've got that themselves (ESS1)

.....the parents have a low self-esteem and they're poor educational background, so that tends to have a knock-on effect, even though it's implicit it's not explicit, they want the best for their children but they don't know how they're going to do it. (HT1) 
This genuine appreciation of the structural limitations experienced by low-income parents is not the only explanation for low aspirations which emerges in these accounts, however. Alternative, and widely discredited, arguments about the culture-of-poverty and the underclass (Bauder, 2002), as well as deficit models of parenting which are still in evidence in some areas of primary schooling (Primary Review, 2007), are also apparent. This is evident in the way headteachers discuss the perceived deficiencies of local cultures, for example as low-income communities are seen to be limited by low aspirations, and by a lack of cultural know how.

The degree of emphasis placed on structural explanation and/or cultural blame varies between headteachers. These variations in emphasis are important, but both explanations allow education professionals to articulate an understanding of why parents have what are deemed low aspirations, without themselves validating these as realistic expectations. In both cases, the intergenerational transmission of dispositions and capital which perpetuates social class differences (Bourdieu, 1986; Dumais, 2006) is partially recognised, as low aspirations are seen in part as a consequence of experience. However, recognition of structural constraints does not mean that alternative forms of working class cultural capital are appreciated by educationalists. As one headteacher (HT5) suggested above, localised strategies for earlier access to employment/ state benefits may be valued over longer periods of study by individuals within the community, yet this deployment of working class cultural capital is regarded as inappropriate by headteachers. Nor is there recognition that these aspirations might well be based on realistic expectations, because these low-income pupils will have poorer educational opportunities and less access to professional employment (regardless of qualifications) than their middle-class counterparts (Nairn et al., 2007). Rather, educational institutions have the power to dictate the types of knowledge which are deemed valuable and worthless through reference to principles based upon middle-class norms (Reay, 2008), and thus aspirations become labelled as low.

Providing a critique of the ways in which aspirations in low-income areas come, through a class-specific analysis, to be labelled as low is important. However, it is not sufficient in itself as it misses some of the moral ambiguities involved in challenging what are deemed to be low aspirations. Specifically, we can see that those educationalists who emphasise the importance of structural constraints reject low aspirations as they want to help their pupils work through these barriers, rather than operate within them, in order to enhance 
their social mobility. They judge these aspirations to be low as they think their pupils deserve better. Equally, even those who, through a class-specific analysis, come to characterise local cultures as deficient, are actively seeking to challenge these in order to provide more varied, better paid, and perhaps easier, lives for their pupils. Thus practices which lead to the labelling of perhaps realistic expectations as low aspirations can be associated with politics which seek to enhance social mobility. In the next section, this uneasy co-existence of middle-class power to define what constitutes an appropriate aspiration, and a progressive politics seeking to enhance social mobility, is further explored through schools' attempts to set an aspiration agenda.

\section{Setting a school aspiration agenda}

In a context where education professionals define many parents' aspirations for their children as low, it is insightful to examine how these same professionals characterise schools' role in transforming children's experiences. Raffo and Dyson (2007) argue that there are two different paradigmatic perspectives in sociological explanations of the links between educational disadvantage and poverty, positions which have largely developed in isolation from one another. Structural accounts see poor educational outcomes, such as low aspirations, as a result of endemic social inequalities, inequalities which education in part reproduces, and thus argue that 'education cannot', as Bernstein famously pointed out, ‘compensate for society’ (Bernstein, 1970 cited in Raffo \& Dyson, 2007: 265). Alternative accounts focus not on structural causes, but on mediating factors through which socioeconomic disadvantage is translated into educational disadvantage, for example through poor schooling, anti-school cultures, and inadequate parenting. Education in this framework is seen as a potential liberator rather than part of the problem, as focused interventions are seen to have the power to tackle what are viewed as problematic practices and cultures.

This split in sociological views of education is not directly reproduced by educators in our sample. Some of the more optimistic professionals thought teachers had a responsibility not just for children's attainment, but also more broadly for the way they grew up:

I think teachers are realising that they're not just accountable for pupil progress and achievement, they're accountable for the way kids grow up (HT4).

They regarded education as a powerful tool for social change, change based not only on formal attainment but also in terms of the education of the whole child (DfES, 2003). Others, however, were much more cautious about the transformative power of education. This was 
not necessarily because they regarded education as part of the problem as a structuralist might do, but because in drawing the two sociological explanations together they saw structural inequalities and what they regarded as cultures of low aspiration to be too great for schools alone to change:

if we talk about disadvantages facing children, you know, they come down to changes in family circumstances, changes in housing, lack of opportunity, low aspirations, the school is only able to have an impact on a few of those things for perhaps a small amount of time. (HT6)

[L]ife chances are not really determined much by what goes on in a classroom but a whole series of other factors in a child's life and the environment in the family and so the solution has to be multi agency (LAE1)

Notwithstanding these differing interpretations of the transformative potential of education, however, educational professions across the board sought to use both the formal and informal curriculum to reshape pupils’ aspirations.

One way schools seek to shape pupils aspirations is by exposing them to a variety of life choices that they would not otherwise see in their family or neighbourhood. Parents in this respect are criticised for failing to give their children access to experiences that would encourage them to aspire beyond local norms:

They [parents] need to be giving their children opportunities to see what's in the outside world so that they can be aspirational. And most of them are not. (HT1) These opportunities which children are seen to be missing, are opportunities to see life beyond their everyday realities. At one level parents were criticised as they did not do a wide range of activities with their children or send them to organised clubs or activities where they might try out new things and meet new people. More fundamentally, their neighbourhoods were characterised as isolated, self-contained worlds, where 'once you've been born here, you stop here' (HT4). In this respect, they had high degrees of bonding social capital which might tie them into their neighbourhood, but little bridging social capital which might give them links into other spheres of life (Cabinet Office Social Exclusion Taskforce, 2008). Children were seen to have limited opportunities to see life off their estate, rarely going to nearby towns or city centres, let alone further afield. Indeed, in echoes of classic culture-ofpoverty thesis (see Bauder, 2001, for a review) there is criticism that children and families do not plan ahead, but rather follow established family patterns that are repeated throughout their locality:

There's a majority I think who don't actually plan that far ahead. You know you talk in assemblies about who wants to go to university and then [they say] 'well got to leave and get a job' ... it's this entrenched history thing of 'that's what my dad did and that's 
what my granddad did' and it's our job as a school to sort of open their horizons and say you know you can do anything you want to. (HT3)

For girls, teachers were explicitly concerned that their ambition was to grow up and have a family, and that some didn't imagine a future where paid work might play a role in their life.

And a lot of the girls....they will say 'oh well I want to grow up and be a mum', and they don’t actually have any aspirations to actually have a job. (HT2)

In this situation, teachers thought challenging girls to raise their aspirations meant signalling that there were better alternatives available to them than the local cultures of younger motherhood:

I mean going to university for a start, that's a major step, even going to a sixth form college that's a huge step, going into a college even. You know a lot of our parents are single parents, mums, who have had babies at fifteen, sixteen, so by offering this we hope to say there is more to this than just having babies, it's very difficult to combat that though because that's well entrenched in the sort of traditions in the area. (HT1)

The notion that growing up to be a mother is no longer a suitable aspiration for a young woman is an interesting one. The impact of both the feminist movement, and neo-liberal welfare reform, has come to mean that the moral agendas surrounding women and motherhood have changed. On the one hand, 40 plus years of second wave feminism has meant that some (though not all) women now have greater opportunities in the workplace and more ability to reconcile family and employment, meaning that there is a more varied range of choices available to them (Crompton, 2006). On the other hand, neo-liberal welfare reform, which has seen a move from redistributive to workfare models, and which posit employment as crucial in reducing welfare dependency and promoting social inclusion (Cochrane \& Etherington, 2007; MacLeavy, 2008), has effectively labelled the choice of younger motherhood immoral. Though theoretically gender-blind, such models have cast the ideal female subject as one who will want to have and raise children alongside participation in paid employment (MacLeavy, 2007). 'From this perspective', as Wilson \& Huntington (2006: 69) argue, 'it seems that teenage mothers have been vilified because they are seen to be actively choosing an alternative path to their middle-class peers, one that does not satisfy contemporary governmental objectives'. The very different nature of the political processes which have challenged women's association with motherhood make these attempts to raise 
aspirations difficult to interpret. Such policies will help some individual girls by providing them with a wider range of life models from which to choose. In this sense, these activities are very positive. However, many will not have access to the middle-class cultural capital which might make these choices a potential reality. In this context, where young women's sub-cultural capital (Bullen \& Kenway, 2004) gives them access to either motherhood, or to low-skilled, low paid employment (Wilson \& Huntington, 2006), it is far from clear whether practices which seek to divert them from early childbearing constitute a raising of their ambitions, or simply a denigration and devaluation of motherhood.

Schools' agenda then is to deliberately challenge local cultures in which teachers judge aspirations as low, and instead to provide insight into a wider range of opportunities for children. As was the case with the community organisations in Bauder's (2001) study, the use of role models was a key tactic in a number of schools. To this end, teachers described asking former pupils who had gone into professional employment to come back into school to talk to children and show them what is possible. In discussions about employment the importance of teaching children that not all jobs are equal, and importantly that the financial rewards for different types of work vary considerably, was also emphasised. In a context where teachers are seeking to challenge local cultures, their own behaviour was also seen as a potentially beneficial model for children, demonstrating to them by example what it means to be an active learner and have a work ethic:

I'd like them [children] to have lots of enrichment activities within the curriculum and outside of the curriculum, a real push in the school on life skills so, and team work, so that they're leaving here with a real sort of primary grounding on what it is to have a work ethic and to be an active part, an active learner. I want them to have role models where they realise that, well certainly in terms of the kind of teachers that I would like here, who are active learners themselves (HT2)

Schools strategies are largely anti-local in the sense that they are encouraging children to 'raise' their aspirations beyond the world they see in their own family and neighbourhood (and as other authors have noted, success in doing so is often seen in terms of a desire to leave such low-income communities (Cabinet Office Social Exclusion Taskforce, 2008; Raco, 2009)). This does not mean, however, that such approaches are confined to school times and school premises; rather, a second strategy seen in schools in this study is to embrace the Extended Services' agenda and use specific aspects of this to reach out beyond the boundaries of the classroom (DfES, 2005; Cummings et al., 2007). Two elements of this 
approach are of interest here. Firstly, schools seek to provide enrichment activities for children as these activities which are not otherwise available locally are seen to have the potential to raise children's self-esteem, develop their skills, and open their eyes to a world beyond their own:

Joe Bloggs might be absolutely rubbish at sitting still in a classroom and listening to how to do maths, but give him an art class and he could be absolutely fantastic and what's wrong with letting a kid feel increased self esteem by doing something that he's good at (ESS1)

[Extra-curricular activities give children] a chance to kind of learn a skill that they might not get as well, you know to do something new that their parents might not take them to do independently. I think quite a lot of our children have quite a limited sort of life out of school in a way, they're not taken to, or very few are taken to a dancing class and gym club and that kind of thing. So the more we can give them in those terms, the more opportunities they'll get (ESS3)

[Extra-curricular activities can give children] the opportunity to do things that they wouldn't normally have done because there are young people, you know parts of [large town], out of [large town], never go into [the town centre] and I'm thinking oh well if they've never been to the seaside, well they've probably never been anywhere have they, if they've not even been to [the town centre]. So to widen those horizons, and that's why maybe they've got low aspirations because they don't see the world out there has got anything to do with them (LAE2)

These enrichment activities, whose provision has been enhanced under the auspices of the Extended Services' agenda, are significant as they can help provide children in these lowincome communities with some of the middle-class cultural capital that their more economically advantaged counterparts 'inherit' from their parents (Bourdieu, 1986; Vincent \& Ball, 2007). Their provision thus goes some (albeit limited) way towards redressing the structural advantages enjoyed by middle-class children, and they are highly valued by education professionals who see their provision as enhancing equal opportunities and the possibility of social mobility.

Secondly, schools also seek to co-opt parents who they, like wider Government, view as crucial in nurturing successful children (H.M. Treasury, 2010). In essence schools are trying to address the culture clash that many pupils experience between home and school life by moulding parents and trying to ensure they nurture their children in ways that both encourage the types of aspirations valued in school and facilitate their achievement. In this context, some education professionals were critical of the perceived insularity of the education system of the past 
In the past we've had the school as an oasis and it's like oh it doesn't matter what happens out here [in the community], in here [the school] we've got, but really actually they spend more time with their parents, they spend more time out of school and you know it is, it's not very helpful is it that you've got one set up working here and then within the community it's very, very different (LAE2)

Instead, they embraced parental support elements of the Extended Services' agenda, providing support to parents as individuals, with the aim of raising their skills levels, and thereby inculcating new attitudes to the role of parents and school:

I think a lot of the parents that come here perhaps didn't have the best experiences of school themselves, so I think a lot of that is kind of supporting them as individuals as well as parents, so it's a case of finding out what they need to better increase their attainment, education levels, so that means that they can in turn help their children's education ..[she continues later].. in the workshops that we're doing, particularly the younger parents, they're the harder to reach [group] and they're the ones that as a school they feel it would be most beneficial to be able to work with, to increase their own attainment levels and give them better understanding of how important their role is as parents, and how important it is that the school supports the parents and the parents support the school (ESS2)

In this instance then, the educational professionals are not seeking to redress children's relative lack of middle class cultural capital (Bourdieu, 1986) through state provision; rather they are seeking to change parents so that they might provide this for children themselves. This element of the policy exemplifies the shift from expectational to aspirational politics (Raco, 2009), as the state is cast as an enabler not a provider, with neighbourhood-based interventions focusing on changing individuals rather than wider social structures. These interventions can have an important impact in the lives of individual parents and families, raising confidence and opening up new opportunities in work and training (Raffo \& Dyson, 2007). However, many schools find that broadscale change is hard to achieve. Most education professionals articulate such difficulties through an emphasis on the need for continued efforts to achieve slow social change; a small minority, however, were clear that education policies were not sufficient in themselves and a focus on the wider problems experienced in low-income communities was also required:

I think really if they're looking improving, improve the lives of their young people ... it should sit within a wider community improvement plan because it's very difficult to have one without the other (LAE2)

Though hardly a call to arms to dismantle an iniquitous class system, or indeed to reject neoliberal policies based on aspirational rather than expectational citizenship (Raco, 2009) which endorse multi-strategy, multi-agency working (Cabinet Office Social Exclusion Taskforce, 
2008), such insights do emphasise the limitations of policies which work at the level of the individual whilst leaving other structural inequalities in place (Raffo \& Dyson, 2007).

\section{Conclusion}

The aims of this paper have been to examine the ways in which education professionals working in low-income areas come to define parental aspirations for their children as low, and to explore education professionals contrasting understandings of appropriate aspirations and how they seek to inculcate these in children through their schooling. In empirical terms, the paper has shown that parental aspirations are defined as low by education professionals because, whilst concentrating on a child's happiness and basic literacy and numeracy skills, they do not conform to normative expectation that valorise higher academic and labour market success. These norms about appropriate ‘educational aspirations’ (Cabinet Office Social Exclusion Taskforce, 2008: 8), in common with other areas of neo-liberal policy development, are not neutral but in reality reflect middle-class practices and are facilitated through middle-class cultural capital (Raco, 2009). Headteachers place great value on raising aspirations as they want to promote social mobility and give their pupils a wider range of opportunities than those currently available in their local communities. Schools therefore seek to reproduce what they regard as higher aspirations, both through formal curriculum, for example lessons on career planning and assemblies on career choices, and through the informal curriculum, in the ways teachers use their own behaviour as a model for children, in their provision of enrichment activities and by their attempts to shape parental practices through Extended Services. In this way the schools attempt both to provide low-income children with some of the middle-class cultural capital their more advantaged peers inherit from their parents (Bourdieu, 1973; Vincent \& Ball, 2007), and seek to reshape parents, rather than the circumstances in which they parent, in order to challenge the disjuncture between home and school environments. This focus on transforming the capacities of individual children and their families living in low-income neighbourhoods, rather than emphasising societal change, can impact positively on the life chances of some individuals. However, it also reflects New Labour's third way approach to politics, in which the door to social mobility is theoretically held open for appropriately aspirational citizen-workers, while the classed-based nature of these idealised neo-liberal child and parenting subjectivities, and the middle-class dispositions and resources on which they rest, remain obscured (Reay, 2008). 
The specificities of these empirical findings are of broader significance for the study of aspirations in geographies of education because they highlight the potential to complement research on aspirations and access to education, with research on the ways aspirations are shaped through the formal and informal curriculum within the educational setting, thus allowing us to contribute to two of the core threads of research in geographies of education (Holloway et al., 2010). This is crucial because while we present these threads separately here - reflecting their sometimes different intellectual heritages - there are clearly links between issues of access to and experiences within education, and thus both need to be on the agenda in geographies of education.

In putting a focus on the ways aspirations are viewed and shaped within schools on the agenda the paper has also sought to set these institutions in their wider national political and local community contexts. On the one hand, this allows us to contribute to current debates about the need for inward and outward looking geographies of education (Hanson Thiem, 2009: Holloway et al., 2010), by demonstrating how attention to social processes within schools can teach us about the importance of education in (re)shaping wider social processes (in this instance as teachers seek through their practices to enhance social mobility) at the same time as we examine how these wider processes shape schooling (for example, as neo-liberal policy developments shape perceptions of what constitute appropriate aspirations). On the other hand, by showing how the local context of the school matters - in this instance because of the perceived importance of parents and communities in shaping aspirations and the apparent disjuncture between home and school cultures - the paper also contributes to a movement within educational research to recouple studies of schooling with the environments in which they are located (Raffo \& Dyson, 2007). We would argue that doing both at the same time - that is reflecting on the links between schools and wider socioeconomic and political processes, at the same time as we examine the way schools are embedded within particular communities - is essential, as it reminds us that this reengagement of educational research with context cannot be a parochial endeavour, as the local is shaped though, and is part of the reproduction of, these wider social processes.

In policy terms the paper lays bare some of the moral ambiguities and political complexities involved in raising children's aspirations. The discourses articulated by some interviewees in this paper can be read as a culturally insensitive attempt by middle class professionals to reshape low-income children in their own image. The raised aspirations in 
question here are aspirations which conform to middle-class professional norms, with lowincome parents being cast as deficient as they have the wrong ambitions for their children and come from the wrong culture. Equally, however, an alternative reading of (other) educational professionals as champions of social mobility is also possible. Some educational professionals were highly cognisant of the structural constraints in which parents operate and raising children's aspirations was seen as a first step on the path to helping them lead an easier life than that of their parents. In effect, most education professionals were challenging the social sorting function of education not by critiquing the wider inequalities that are endemic in capitalism, but in trying to ensure some level of social mobility by helping their pupils to benefit more from (or at the very least be less disadvantaged by) that system. Some might cast this kind of policy intervention as a micro tool for a macro problem (Raffo \& Dyson, 2007) as it ultimately leaves a system with winners and losers intact. However, while we would agree that such practices are not sufficient to produce radical change, they can be better - when based on an appreciation of the limiting structural conditions in which many low-income parents must care for their children - than doing nothing at all.

\section{Acknowledgements}

This research was funded through Sarah Holloway’s Philip Leverhulme Prize, and the authors gratefully acknowledge The Leverhulme Trust's support. We would also like to thank Gavin Brown and the anonymous referees for their comments on an earlier draft of this paper.

\section{References}

Archer, L., 2007. Diversity, equality and higher education: a critical reflection on the ab/uses of equity discourse within widening participation. Teaching in Higher Education, 15(5), 63553.

Bauder, H., 2001. 'You're good with your hands, why don’t you become an auto mechanic': neighborhood context, institutions and career development. International Journal of Urban and Regional Research, 25(3), 593-608.

Bauder, H., 2002. Neighbourhood effects and cultural exclusion. Urban Studies, 39(1), 8593. 
Bourdieu, P. (1973) Cultural reproduction and social reproduction. In R. Brown (Ed.), Knowledge, education, and cultural change: Papers in the sociology of education, Tavistock, London, 71-112

Bourdieu, P. (1986) The Forms of Capital. In J.G.Richardson (Ed) Handbook for Theory and Research for the Sociology of Education, Oxford, Greenwood Press, 241-258.

Brehony, K.J., 2005. Primary schooling under New Labour: the irresolvable contradictions of excellence and enjoyment. Oxford Review of Education, 31(1), 29-46.

Bullen, E. and Kenway, J., 2004. Subcultural capital and the female 'underclass'? A feminist response to underclass discourse. Journal of Youth Studies, 7(2), 141-153

Burke, P.J., 2006. Men accessing education; gendered aspirations. British Educational Research Journal, 32(5), 719-733.

Butler, T. and Hamnett, C., 2007. The geography of education: introduction. Urban Studies 44, 1161-74.

Cabinet Office Social Exclusion Taskforce (2008) Aspirations and attainment amongst young people in deprived communities. Analysis and discussion paper. Available at: http://www.cabinetoffice.gov.uk/media/109339/aspirations_evidence_pack.pdf. [Last accessed 29.9.10].

CACI, 2010. ACORN: User Guide. CACI, London. Available from: http://www.caci.co.uk/acorn2009/CACI.htm [Accessed $12^{\text {th }}$ July 2010].

Cochrane, A. and Etherington, D., 2007. Managing local labour markets and making up new spaces of welfare. Environment and Planning A, 39, 2958-74.

Cao, H.H., 2008. Spatial inequality in children's schooling in Gansu, Western China: reality and challenges. Canadian Geographer 52(3), 331-50. 
Collins, D. and Coleman, T. 2008. Social geographies of education: looking within, and beyond, school boundaries. Geography Compass, 2, 281-99.

Cooper, M.A., 2009. Dreams deferred?: the relationship between early and later postsecondary educational aspirations among racial/ethnic groups. Educational Policy, 23, 615-50.

Crompton, R., 2006 .Employment and the Family: The Reconfiguration of Work and Family Life in Contemporary Societies. Cambridge University Press, Cambridge.

Crozier, G., 2009. South Asian parents' aspirations versus teachers' expectations in the United Kingdom. Theory into Practice, 48, 290-96.

Cummings, C., Dyson, A., Muijs, D., Papps, I., Pearson, D., Raffo, C., Tiplady, L., Todd, L. and Crowther, D., 2007. Evaluation of the Full Service Extended Schools Initiative: Final DfES Report RR 759. Manchester, University of Manchester.

DCSF (Department for Children, Schools and Families), 2008. Departmental Report 2008. London, Stationery Office.

DCSF, 2009. 3.1 Overview and school inspections. Available from:

http://www.dcsf.gov.uk/trends/index.cfm?fuseaction=home.showIndicatorandcid=3andiid=9 [Accessed $10^{\text {th }}$ August 2009].

DfES, 2003. Every Child Matters. Norwich, Stationery Office.

DfES, 2005. Extended schools: Access to opportunities and services for all - A prospectus. Nottingham, DfES Publications.

Dumais, S.A. , 2006. Early childhood cultural capital, parental habitus, and teachers' perceptions. Poetics, 34(2), 83-107. 
Freytag, T., 2003. Bildungswesen, Bildungsverhalten und kulturelle Identität: Ursachen für das unterdurchschnittliche Ausbildungsniveau der hispanischen Bevölkerung in New Mexico. Heidelberg: Selbstverlag des Geographischen Instituts der Universität Heidelberg.

Gilby, N., Hamlyn, B., Hanson, T., Romanou, E., Mackey, Y., Clark, J., Trikka, N. and Harrison, M., 2008. National Survey of Parents and Children. Family Life, Aspirations and Engagement with Learning 2008. Research Report No. DSCF - RR059. Available at http://publications.dcsf.gov.uk/eOrderingDownload/DCSF-RR059.pdf [Accessed $21^{\text {st }}$ April 2010].

Gillies, V., 2006. Working class mothers and school life: exploring the role of emotional capital. Gender and Education 18, 281-93.

Gutman, L.M. and Akerman, R., 2008. Determinants of Aspirations, Centre for Research on the Wider Benefits of Learning Research Report 27, Institute of Education, 20 Bedford Way, London, WC1H 0AL.

Haylett, C., 2001. Illegitimate subjects?: abject whites neoliberal modernisation and middleclass multiculturalism. Environment and Planning D: Society and Space, 19, 351-70.

H.M. Treasury, Department for Children, Schools and Families, and Department for Work and Pensions (2010) Ending Child Poverty: Mapping the Route to 2010. Available from: http://www.hm-treasury.gov.uk/d/budget2010_childpoverty.pdf [Accessed 21st April 2010].

Hanson Thiem, C., 2009. Thinking through education: the geographies of contemporary educational restructuring. Progress in Human Geography, 33, 154-73.

Holdsworth, C., 2006. 'Don't you think you're missing out, living at home?' Student experiences and residential transitions. Sociological Review, 54, 495-519. 
Holloway, S.L., Hubbard, P., Jöns, H. and Pimlott-Wilson, H. (2010) Geographies of education and the significance of children, youth and families. Progress in Human Geography, 34(5): 583-600

Hopkins, P., 2006. Youth transitions and going to university: the perceptions of students attending a geography summer school access programme. Area 38, 240-47.

Jeffrey, C., Jeffrey, P. and Jeffrey, R., 2007. Degrees without freedom? Education, masculinities, and unemployment in north India. Stanford, CA: Stanford University Press.

Johnston, R., Wilson, D. and Burgess, S., 2007. Ethnic segregation and educational performance at secondary school in Bradford and Leicester. Environment and Planning A, 39, $609-29$.

Jones, G.A. and Chant, S., 2009. Globalising initiatives for gender equality and poverty reduction: exploring 'failure' with references to education and work among urban youth in The Gambia and Ghana. Geoforum, 40, 184-196.

MacLeavy, J., 2007. Engendering New Labour’s workfarist regime: exploring the intersection of welfare state restructuring and labour market policies in the UK. Gender Place and Culture, 14, 721-43.

MacLeavy, J., 2008. Neoliberalising subjects: the legacy of New Labour’s construction of social exclusion in local governance. Geoforum, 39, 1657-66.

McDowell, L., 2002. Masculine discourses and dissonances: strutting 'lads', protest masculinity, and domestic respectability. Environment and Planning D: Society and Space, 20, 97-119.

Nairn, K., Higgins, J. and Ormond, A., 2007. Post-school horizons: New Zealand's neoliberal generation in transition. International Studies in Sociology of Education, 17(4), 349366. 
ONS (Office for National Statistics) 2004 Children's dental health: social factors Available from:

http://www.statistics.gov.uk/CCI/nugget.asp?ID=1000andPos=1andColRank=2andRank=224 [Accessed $26^{\text {th }}$ November 2008].

ONS (2005) KS06 Ethnic group, Census 2001: Key Statistics for the rural and urban area classification 2004. Available from:

http://www.statistics.gov.uk/StatBase/ssdataset.asp?vlnk=8919andPos=andColRank=1andRa $\underline{\mathrm{nk}=240}$ [Accessed $5^{\text {th }}$ November 2009].

ONS (2007) Neighbourhood Statistics: Any Key Working Age Benefit. Available from: http://neighbourhood.statistics.gov.uk/dissemination/LeadHome.do [Accessed 10th October 2009].

Patterson, L., 2003. The three educational ideologies of the British Labour Party, 1997-2003. Oxford Review of Education, 29(2), 165-185.

Primary Review (2007) Community Soundings: the Primary Review regional witness sessions. Cambridge: University of Cambridge Faculty of Education Punch, S., 2004. The impact of primary education on school-to-work transitions for young people in rural Bolivia. Youth and Society 36, 163-82.

Raco, M. (2009) From expectations to aspirations: state modernisation, urban policy, and the existential politics of welfare in the UK. Political Geography 28(7), 436-44.

Raffo, C. and Dyson, A., 2007. Full service extended schools and educational inequality in urban contexts - new opportunities for progress? Journal of Education Policy, 22(3), 263282. 
Reay, D,. 1998. Class Work: Mothers Involvement in their Children’s Primary Schooling (RoutledgeFalmer, London)

Reay, D., 2008. Tony Blair, the promotion of the 'active' educational citizen, and middleclass hegemony. Oxford Review of Education, 34, 639-50.

Stenning, A., 2008. For working class geographies. Antipode, 40.1, 9-14

Stewart, E.B., Stewart, E.A. \& Simons, R.L., 2007. The effect of neighbourhood context on the college aspirations on African American adolescents. American Educational Research Journal, 44(4), 896-919.

Strand, S. and Winston, J., 2008. Educational aspirations in inner city schools. Educational Studies, 34(3), 249-267.

Taylor, R., 2005. Lifelong learning and the Labour governments 1997-2004. Oxford Review of Education, 31(1), 101-118.

Vincent, C. and Ball, S. J., 2007. 'Making up’ the middle-class child: families, activities and class dispositions. Sociology, 41, 1061-77.

Vincent, C., Braun, A. and Ball, S. J., 2008. 'It's like saying 'coloured' ': understanding and analysing the urban working classes. Sociological Review, 56, 61-77.

Warrington, M., 2005. Mirage in the desert? Access to educational opportunities in an area of social exclusion. Antipode, 37, 796-816.

Waters, J.L., 2009. In pursuit of scarcity: transnational student, 'employability', and the MBA. Environment and Planning A, 41(8), 1865-83.

Whitty, G., 2009. Evaluating ‘Blair's Educational Legacy?’: some comments on the special issue of Oxford Review of Education. Oxford Review of Education, 35, 267-80. 
Wilkin, A., White, R. and Kinder, K., 2003. Towards extended schools: a literature review.

Slough, National Foundation for Educational Research.

Wilson, H. and Huntington, A., 2006. Deviation (m)others: the construction of teenage

motherhood in contemporary discourse. Journal of Social Policy, 35(1), 59-76.

\footnotetext{
i Throughout the paper we show the contested nature of debates about low, appropriate and raised aspirations. As this contestation is evident in the argument, we do not place inverted commas around the terms, other than in the title.

${ }^{\text {ii }}$ Furthermore, we approximate figures in our description of Hortonshire and do not divulge some data sources.

iii These terms express the socio-economic differences between the communities the schools serve; the circumstances of individual families may differ from this.

iv ACORN is a geodemographic segmentation of the UK's population which divides small neighbourhoods, postcodes, or consumer households into 5 categories, 17 groups and 56 types. The information, used both by Government and the private sector, is provided by CACI: http://www.caci.co.uk
} 